\title{
Detection of Methicillin-Resistant Staphylococcus aureus in Diabetic Foot Infections
}

\author{
Basavaraj C Metri* and P. Jyothi \\ Department of Microbiology, Shri B M patil Medical College Hospital and \\ Research center, Vijayapur, India \\ *Corresponding author
}

\section{Keywords}

Staphylococcus

aureus,

Colonization, oxacillin

Article Info

Accepted:

15 January 2020

Available Online:

10 February 2020

\section{A B S T R A C T}

Diabetes mellitus is a serious public health problem and remains an important cause of morbidity and mortality. The Indian diabetic population is expected to increase to 57 million by the year 2025 and 87 million by 2030. Methicillin-resistant Staphylococcus aureus (MRSA) has emerged as a serious and common problem in patients with diabetic foot Infection. Colonization with MRSA may result in prolonged hospital stay and excessive direct economic cost. Until now few studies are available about methicillinresistant S. aureus (MRSA) strains isolated in diabetic foot infections in this part of India. Therefore the study was conducted to know the prevalence and antibiotic resistance pattern of MRSA isolated among the diabetic foot Infection. Materials and methods: The study was conducted in the Department of Microbiology, Shri B.M Patil Medical College Hospital and Research center, Vijayapur. A total of 96 patients with history of diabetes which yielded S. aurius were included in the study. Antimicrobial susceptibility testing of the isolates was performed by Kirby Bauer disc diffusion method. MRSA were detected by Cefoxitin Disc Diffusion Test, Oxacillin Disk Diffusion Method and by mecA gene PCR The male DFI patients formed the sources for majority of the isolates with percentage of $55.2 \%$. patients with DFI were more among the elderly people age group of 41-60, followed by 61-8- age group. In the present study, isolation rate of MRSA was $44 \%$ in our study. MRSA isolates were more resistant then MSSA isolates. Detection of mecA gene is considered the gold standard for MRSA confirmation. In our study, the PCR detected 44 isolates as MRSA and the 52 isolates as MSSA. Cefoxitin and Oxacillin detected 42 and 35 isolates as MRSA respectively. Diabetic foot infections (DFI) are very serious and life threatening if not treated in time and with proper antibiotics. MRSA are one of the important causes of diabetic foot Infection and hence should be identified early for better outcome. cefoxitin disc is better than oxacillin disc for the detection of methicillin resistance. Results of cefoxitin disc diffusion test are as good as PCR used for mecA gene, and thus the cefoxitin can be used for identification of MRSA in setting where PCR is not available. 


\section{Introduction}

Diabetes mellitus is a serious public health problem and remains an important cause of morbidity and mortality. (Zaini et al., 2000)The Indian diabetic population is expected to increase to 57 million by the year 2025(Shakil et al., 2010).and 87 million by 2030.(Tiwari et al., 2012)It is well known that patients with poorly controlled DM are at risk of developing diabetic complications such as pedal ulcers with or without gangrene, retinopathy, neuropathy and macro vascular complications.

(Benwan et al., 2012) Diabetic foot infections (DFIs) are common, complex and costly complications of DM. In addition to causing severe morbidities, they account for the largest number of diabetes related hospital inpatient days and are the most common proximate, non-traumatic cause of amputations. (Lipsky et al., 2004)

Foot complications such as foot ulcer constitute a major public health problem and impose a heavy burden on health services. Foot infections are responsible for the majority of diabetes - associated hospital admissions. It was estimated that approximately $15 \%$ of all diabetics develop foot ulcers and eventually progress to osteomyelitis. (Ramsey et al., 2004)

The impaired micro-vascular circulation in patients with a diabetic foot limits the access of phagocytes, thus favoring the development of an infection. The local injuries and the improper foot wear further compromise the blood supply in the lower extremities.

While the foot infections in persons with diabetes are initially treated empirically, a therapy which is directed at the known causative organisms may improve the outcome. (Citron et al., 2007).
Optimal management of DFIs can reduce the incidence of infection-related morbidities, the need for and duration of hospitalization, and the incidence of major limb amputation. Early identification of lesions, prompt initiation of appropriate antibiotic therapy, aggressive surgical debridement of necrotic soft tissue and bone, and modification of host factors are all equally important for a successful clinical outcome. (Lipsky et al., 2004)

Reports from western countries have found that Staphylococcus aureus and $\beta$-haemolytic streptococci are the main causative pathogens (Dang et al., 2003). In appropriate antibiotic usage contributes to the increasing prevalence of multidrug-resistant organisms, notably methicillin-resistant S. aureus (MRSA).

Methicillin-resistant Staphylococcus aureus (MRSA) has emerged as a serious and common problem in patients with diabetic foot ulcers. Infection/ colonisation with MRSA may result in prolonged hospital stay and excessive direct economic cost. (Tentolouris et al., 2006)

Until now few studies are available about methicillin-resistant S. aureus (MRSA)strains isolated in diabetic foot infections in this part of India. Therefore the study was conducted to know the prevalence and antibiotic resistance pattern of MRSA isolated among the diabetic foot Infection.

\section{Materials and Methods}

The study was conducted in the Department of Microbiology, Shri B.M. Patil Medical College Hospital and Research center, Vijayapur. A total of 96 patients with history of diabetes which yielded S. aurius were included in the study after approval of institutional Ethics Committee. Samples were collected from the deeper portion of the ulcers by using 2 sterile swabs which were dipped in sterile glucose broth. The samples were 
collected by making a firm, rotatory movement with the swabs (Shanmugan et al., 2013).

\section{Statistical analysis}

Values were expressed in terms of Mean \pm SD. Analysis was done by using SPSS software version 16 . $\mathrm{P} \leq 0.05$ was considered statistically significant.

\section{Inclusion criterion}

Patients with history of diabetes which yielded $S$. aurius were included in the study

\section{Exclusion criterion}

Patients without history of diabetes were excluded from the study Specimens were screened by preliminary Gram's stain andthen inoculated on $10 \%$ sheep blood agar and Mac Conkey's agar. $S$. aureus were identified by conventional techniques. Antimicrobial susceptibility testing of the isolates was performed by Kirby Bauer disc diffusion method using following discs. penicillinG(10unit); cloxacillin $(30 \mu \mathrm{g})$; cephalexin (30 $\mu \mathrm{g})$; cefuroxime $(30 \mu \mathrm{g})$; tetracycline $(30 \mu \mathrm{g})$; erythromycin $(15 \mu \mathrm{g})$; gentamicin $(10 \mu \mathrm{g}) ; \quad$ ciprofloxacin $(5 \mu \mathrm{g})$; pefloxacin $(5 \mu \mathrm{g}) ; \quad$ Cefoperazone / salbactam $(75 \mu \mathrm{g} / 30 \mu \mathrm{g}) ; \quad$ azithromycin $(15 \mu \mathrm{g})$; linezolid $(15 \mu \mathrm{g})$. Vancomycin $(30 \mu \mathrm{g})$; piperacillin / tazobactam $(100 \mu \mathrm{g} / 10 \mu \mathrm{g}) ; \quad$ amoxicillin /clavulanic acid $(20 \mu \mathrm{g} / 10 \mu \mathrm{g})$.

The data were recorded and analyzed at the completion of the study as per recommendations of the CLSI. (M100-S21, Clinical and Laboratory Standards Institute, 2011)

\section{Detection of MRSA}

The cefoxitin disc diffusion test

The Cefoxitin disc diffusion method was carried out on Mueller-Hintonagar by using a $30 \mu \mathrm{g}$ cefoxitin disc. Inoculum was prepared and compared with $0.5 \mathrm{McF}$ arland turbidity constant. Mueller-Hintonagar was inoculated and excess was removed. Cefoxitin $30 \mathrm{mcg}$ discs were applied with force ps and pressed gently to ensure even contact with the medium. The plates were incubated for 1824 hours at $37^{\circ} \mathrm{c}$. Interpretation was done using the Kirby-Bauer charts. An inhibition zone diameter of $\leq 21 \mathrm{~mm}$ was reported as methicillin resistant.(Isenberg et al., 2004)

\section{The Oxacillin Disk Diffusion Method}

The Oxacillin disk $(1 \mu \mathrm{g})$ diffusion method was carried out on Mueller-Hintonagar which was supplemented with $4 \% \mathrm{NaCl}$ to detect MRSA according to the CLSI guide lines. The isolates were considered as resistant when the diameter of inhibition was $\leq 10 \mathrm{~mm}$. (Brown et al., 2005)

Genotypic detection of MRSA by PCR (mecAgene) (Vanpelt et al., 2008)

DNA Extraction Procedure was done by Modified Proteinase-K method. MRSA strains were amplified by conventional PCR. Following set of PCR primers were used which were specific to Methicillin resistant $S$. aureus (Boucher et al., 2008).

\section{Forward Primer}

5'-TGC TATCCA CCC TCAAAC AGG-3' Reverse Primer: 3'-AAC GTTGTAACCA CCCCA AGA-5' AMPLIQON RED 2X Master mix was used which contain following reagents Tris-HCL pH 8.5, (NH4)2SO4, 3mM $\mathrm{MgCl} 2,0.2 \%$ Tween $20,0.4 \mathrm{mM}$ of each dNTP, 0.2 units/ $\mu$ Ampliqon Taq DNA Polymerase. The PCR conditions were as follows:

Initial denaturation (940C, 5min), Denaturation (940C, 1min), 
Annealing (500C,1 min),

Extension (720 C, $2 \mathrm{~min}$ ),

Final extension $\left(72^{\circ} \mathrm{C}\right.$ for $\left.5 \mathrm{~min}\right)$.

Reagents with their company names: PCR.

Master mix: Ampliqon Oligonucleotide.

\section{Primers}

Bio serve India pvt. Ltd.

\section{Instruments}

Thermal cycler: Applied Biosystems, USA Electrophoresis apparatus: Bio bee Tech, Bangalore. Gel Documentation system: Major Science, USA.

The PCR was carried out for MRSA strains with MRSA specific primer set. After PCR, the agarose gel electrophoresis was done where PCR amplified products were run on a $2 \%$ agarose gel.

After running the electrophoresis, the amplified products will get separated on the gel according to the product size which was determined while choosing a primer.

We had chosen a primer set which gives amplified product of size 280 base pair.

So the well which gives DNA band of 280 base pair is considered positive, whereas the well which does not have any DNA band is indicated as negative.

The size or the position of the DNA band can be known by running the DNA ladder simultaneously with each gel

\section{Results and Discussion}

As shown in table 1 the male DFI patients formed the sources for majority of the isolates with percentage of 55.2. As shown in table 2,patients with DFI were more among the elderly people age group of 41-60, followed by 61-8-age group. As shown in table3, in the present study, isolation rate of MRSA was $44 \%$ in our study.

Table. 4 shows that Detection of mecA gene is considered the gold standard for MRSA confirmation. In our study, the mecA gene PCR detected 44 isolates as MRSA and the 52 isolates as MSSA. Cefoxitin and Oxacillin detected 42 and 35 isolates as MRSA respectively

Table.1 Distribution of patients according to sex

\begin{tabular}{|l|c|c|}
\hline SEX & N & \% \\
\hline Female & 43 & 44.8 \\
\hline Male & 53 & 55.2 \\
\hline Total & 96 & 100 \\
\hline
\end{tabular}

Table.2 Association of age with sex among patients with DFI

\begin{tabular}{|l|c|c|c|c|}
\hline \multirow{2}{*}{ AGE (YRS) } & \multicolumn{3}{|c|}{ Male } & \multicolumn{2}{c|}{ Female } \\
\hline $\mathbf{1 - 4 0}$ & $\mathbf{N}$ & $\mathbf{\%}$ & $\mathbf{N}$ & $\%$ \\
\hline $\mathbf{4 1 - 6 0}$ & 6 & 11.3 & 5 & 11.6 \\
\hline $\mathbf{6 1 - 8 0}$ & 33 & 62.6 & 25 & 58.2 \\
\hline Above 80 & 12 & 22.6 & 8 & 18.6 \\
\hline & 2 & 3.7 & 5 & 11.6 \\
\hline
\end{tabular}


Table.3 Distribution of MRSA and MSSA among patients with DFI

\begin{tabular}{|l|c|c|}
\hline S. aureus & N & $\%$ \\
\hline MSSA & 5 & 54 \\
\hline MRSA & 4 & 46 \\
\hline Total & 9 & 100 \\
\hline
\end{tabular}

Table.4 Comparative results of phenol typic methods with PCR

\begin{tabular}{|l|c|c|c|c|c|c|}
\hline \multicolumn{1}{|c|}{ TEST } & MRSA & Sensitivity & Specificity & PPV & NPV & Accuracy \\
\hline METHODS & & & & & & \\
\hline Oxacillin & 35 & $79.5 \%$ & $94.9 \%$ & 93.7 & 83.1 & $87.5 \%$ \\
\hline Cefoxitin & 42 & $95.4 \%$ & $100.0 \%$ & 100.0 & 96.1 & $97.9 \%$ \\
\hline PCR & 44 & $100.0 \%$ & $100.0 \%$ & 100.0 & 100.0 & $100.0 \%$ \\
\hline
\end{tabular}

Table.5 Comparison of resistance pattern of MRSA and MSSA among patients of DFI

\begin{tabular}{|l|c|c|c|c|c|}
\hline \multirow{2}{*}{ Antibiotic susceptibility pattern } & \multicolumn{2}{|c|}{$\begin{array}{c}\text { MRSA } \\
\text { (N=44) }\end{array}$} & \multicolumn{2}{|c|}{ MSSA (N=52) } & \\
\cline { 2 - 5 } & $\mathbf{R}$ & $\mathbf{\%}$ & $\mathbf{R}$ & $\mathbf{\%}$ & pvalue \\
\hline PENICILLIN-G & 43 & 97.7 & 45 & 83.3 & $0.048^{*}$ \\
\hline EYTHROMYCIN & 26 & 59 & 33 & 63.5 & 0.661 \\
\hline TETRACYCLINE & 12 & 27.3 & 8 & 15.4 & 0.153 \\
\hline CEPHALEXIN & 31 & 70.5 & 24 & 46.2 & $0.016^{*}$ \\
\hline CLOXACILLIN & 20 & 45.5 & 17 & 32.7 & 0.200 \\
\hline PEFLOXACIN & 35 & 79.5 & 31 & 59.6 & $0.036^{*}$ \\
\hline PIPERACILLIN/TAZOBACTAM & 17 & 38.6 & 8 & 15.4 & $0.010^{*}$ \\
\hline CEFOPERAZONE /SULBACTAM & 17 & 38.6 & 15 & 28.8 & 0.311 \\
\hline GENTAMICIN & 13 & 29.5 & 11 & 21.2 & 0.344 \\
\hline CIPROFLOXACIN & 35 & 79.5 & 31 & 59.6 & $0.036^{*}$ \\
\hline AMOXICILLIN/CLAVULANATE & 32 & 72.7 & 29 & 55.8 & 0.085 \\
\hline CEFUROXIME & 21 & 47.7 & 14 & 26.9 & 0.035 \\
\hline AZITHROMYCIN & 21 & 47.7 & 18 & 34.6 & 0.192 \\
\hline VANCOMYCIN & 9 & 20.5 & 6 & 11.5 & 0.231 \\
\hline LINEZOLID & 8 & 18.2 & 3 & 5.7 & 0.057 \\
\hline
\end{tabular}

Note:* significant at 5\% level of significance $(\mathrm{p}<0.05)$ 


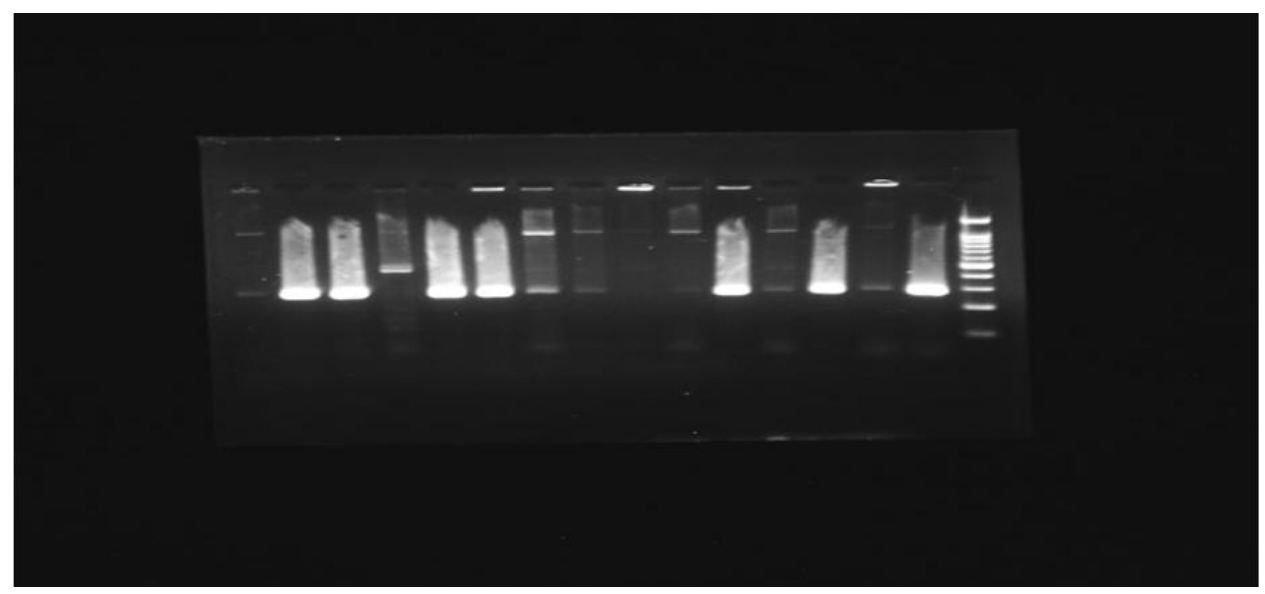

Results of mecAgene(left to right)

Lane1: Molecular weight markerLane2: MRSA ATCC43300

Lane3: MSSA ATCC25923

Lane4, 6, 11,12,14 and 15: MRSA isolates from clinical samples (280 BP)

Lane5, 7-10, 13, and 16: MSSA isolates from clinical sample

Diabetic foot ulcers are more prone to bacterial infections that spread rapidly, leading to irreversible tissue damage. Complications usually begin with an unrecognized foot ulcer in a patient with an insensate foot which gets infected, leading to significant morbidity and lower extremity amputations. Patterns of microbial infection are not consistent in patients with diabetic foot infections and therefore repeated evaluation of microbial characteristics and their antibiotic sensitivity is necessary for selection of appropriate antibiotics. Progression of infection in diabetic foot is a result of suppressed immune status, delayed diagnosis, underestimation of extent of infection, or suboptimal (if not inappropriate) antimicrobial therapy. (Tiwari et al., 2012)

Diabetic patients often have chronic nonhealing foot ulcers due to several underlying factors such as neuropathy, high plantar pressures and peripheral arterial disease. Such chronic long-standing ulcers are more prone for infection which further delays the wound healing process.(Sivaraman et al., 2011) as shown in table1, in the present study, MRSA was pre dominantly isolated from males $(55 \%)$ which correlated with study of (Raja et al., 2007).

As shown in table 2, patients with DFI were more among the elderly people age group of 41-60, followed by 61-80 age group this finding correlates well with (Shanmugam et al., 2013).who reported a similar findings.

Management of diabetic foot infections usually requires combination therapy with surgical drainage and debridement or osseous resection. The choice of antibiotic therapy is influenced by the sensitivity of the encountered bacterial pathogens.

Accurate microbiological working is imperative to the choice of appropriate antibiotic therapy for diabetic foot infections. Several drugs have been used to treat nonlimb-threatening infections including betalactamase inhibitors, third generation cephalosporins, aminoglycosides, ampicillin, penicillin, quinolones, piperacillin tazobactam and linezolids. Third-generation cephalosporins are not active against enter ococci and an aerobes, while fluoroquionol one shave low activity against streptococci 
and anaerobes (Raja et al., 2007).

The antibiogram results in this study suggest that pathogens remain sensitive to a number of agents. Imipenem was equally effective against Gram-negative bacilli and Grampositive cocci. Vancomycin was found to be the most effective drug overall against Grampositive organisms. These findings are consistent with a previous study. Our findings illustrate that antimicrobial therapy needs to be selected based on actual culture findings and antimicrobial sensitivity patterns of isolates. (Raja et al., 2007)

Antibiotic susceptibility pattern revealed a high resistance to routinely used antibiotics. Resistance to quinolones i,e. ciprofloxacin and pefloxacin were high in this study. This is comparable to the study done by (Sanjana et $a l ., 2010)$ in Nepal. Resistance to cephalexin was also much higher in this study. This is consistent with to the study carried out by (Sanjana et al., 2010) who reported the similar resistant rate to cephalexin. (Majumder et al., 2001).also revealed that resistance to various antibiotics with methicillin resistant strains was $\mathrm{s}$ higher in comparison to methicillin-sensitive isolates.

Factors responsible for to drug resistance in MRSA are as follows. Antibiotics are available without prescription at drug stores or even at general stores and injudiciously used in communities, animal husbandries, and fisheries and use of allopathic drugs by traditional practitioners. (Metri et al., 2014)

Detection of mecA gene is considered the gold standard for MRSA confirmation. In our study, the mecA gene PCR detected 44 isolates as MRSA and the 52 isolates as MSSA. Recent studies including our $\mathrm{s}$ indicate that cefoxitin disc diffusion test is better than most of the phenotypic methods like oxacillin disc diffusion and oxacillin screen agar testing and is now an accepted method for the detection of MRSA by many reference groups including CLSI. The accurate and early determination of methicillin resistance is of key importance in the prognosis of infections caused by $\mathrm{S}$. aureus. (Anand et al., 2003) T

his higher sensitivity to cefoxitin can be explained by the increased expression of the mecA-encoded protein PBP2a, cefoxitin being an inducer of the mecA gene. (Anand $e t$ al., 2003) Our study reveals that cefoxitindisc is better than oxacillin disc for the detection of methicillin resistance.

Results of cefoxitin disc diffusion test is as good as PCR used for mecA gene, and thus the cefoxitin can be used for identification of MRSA and the test can be used as cost effective method when compared PCR for detection of MRSA .

Diabetic foot infections (DFI) are very serious and life threatening if not treated in time and with proper antibiotics. MRSA are one of the important causes of DFI, and hence should be identified early for better outcome. Cefoxitin disc is better than oxacillin disc for the detection of methicillin resistance. Results of cefoxitin disc diffusion test are as good as PCR used for mecA gene, and thus the cefoxitin can be used for identification of MRSA in setting where PCR is not available.

\section{References}

Anand KB, Agrawal P, Kumar S, K Kapila K. Comparison of cefoxitin disc diffusion test, oxacillin screen agar, and PCR for mecA gene for detection of MRSA. Indian $\mathbf{J}$ Med Microbiol 2003;27: 27-9.

Benwan KA, Mulla AA, Rotimi VO. A study of the microbiology of diabetic foot infections in a teaching hospital in Kuwait.J Infect Public health. 2012; 5(1):1-8.

Boucher HW, Corey GR. Epidemiology of methicillin - resistant Staphylococcus aureus. ClinInfect Dis 2008;46(Suppl 5):S344-S9 
BrownDF, EdwardsDI, HawkeyPM, MorrisonD, RidgwayGL, Towner KJ, et al., Guidelines for the laboratory diagnosis and susceptibility testing of methicillin - resistant Staphyloccocus aureus. JAntimicrobChemother 2005; 56:1000-18.

Citron DM, Goldstein EJC, Merriam VC, Lipsky BA.Bacteriology of moderate to severe diabetic foot infections and invitro activity of antimicrobial agents.J ClinMicrobiol.2007; 45 (9):2819-28.

Dang CN, Prasad YD, Boulton AJ, Jude EB (2003) Methicillin resistant Staphylococcus aureus in the diabetic foot clinic: a worsening problem. Diabet Med 20:159-161

Isenberg $\mathrm{HD}$, editor. Clinical microbiology procedures hand book. 2nded. Washington DC: ASM Press;2004.

Lipsky BA, Berendt AR, Deery HG, Embil JM, Joseph WS, Karchmer AW, et al., Diagnosis and treatment of diabetic foot infections. Clin Infect Dis 2004;39: 885-910.

Lipsky BA. A report from the international consensus on diagnosing and treating the infected diabetic foot. Diabetes Metab Res Rev 2004;20(Suppl. 1):S68-77.

MajumderD, BordoloiJS, PhukanAC, MahantaJ. Antimicrobial susceptibility pattern among methicillin resistant staphylococcus isolates in Assam. Indian J Med Microbiol2001;19:138-40.

Metri BC, Peerapur BV, P Jyothi.Comparison of antimicrobial resistance pattern of hospital-and community-acquired Methicillin resistant Staphylococcus aureus.J Chem Pharm Res 2014;6:201-5.

Raja NS. Microbiology of diabetic foot infections in a teaching hospital in Malaysia: A retrospective study of 194 cases. $J$ Microbiolimmunol infect. 2007; 40(1): 39-44.

Ramsey SD, Newton K, Blough D, McCulloch DK, SandhuN, ReiberGE, et al., Incidence,out comes, and cost of foot ulcers in patients with diabetes. Diabetes Care.1999;22:382-7.

RaoVenkatakrishnaI, BhatKishore G, Kugaji ManoharS, ManjulaPV. Detection of methicillin Resistancein Staphylococcus aureus: Comparison of Disc diffusion and MIC with mecA gene detection by PCR. Int JPharm BioSci. 2011;1:518-21.

Sanjana RK, Shah R, Chaudhary N, Singh YI. Prevalence and antimicrobial susceptibility pattern of methicillin-resistant Staphylococcus aureus(MRSA) in CMSteaching hospital: a preliminary report. J College Med Sci Nepal 2010; 6:1-6.

Shakil S, Khan AU. Infected foot ulcers in male and female diabetic patients: A clinicobioinformative study.Ann ClinMicrobiolAntimicrob. 2010; 9:1-10.

Shanmugam P, Jeya M, Susan SL. The Bacteriology of Diabetic Foot Ulcers, with a Special Reference to MultidrugResistant Strains.J ClinDiagnos Res. 2013; 7(3): 4415 .

Sivaraman U, Kumar S, Joseph NM, Easow JM, Kandhakumari G. Microbiological study of diabetic foot infections. Indian J Med Specialities.2011; 2(1):12-17.

Tentolouris N, Petrikkos G, Vallianou N et al., Prevalence of methicillin resistant Staphylococcus aureus in infected and uninfected diabetic foot ulcers. ClinMicrobiol Infect 2006; 12: 186-189.

The Clinical and Laboratory Standards Institute. Performance Standards for Antimicrobial Susceptibility testing, twenty first informational supplement, M100-S21, Clinical and Laboratory Standards Institute, 2011.

Tiwari S, Pratyush DD, Dwivedi A, Gupta SK, RaiM,Singh SK.Microbiological and clinical characteristics of diabetic foot infections in northern India.J Infect DevCtries2012; 6(4):329-32.

VanpeltE,BelkumVAV,HaysJP.PrinciplesandTec hnical aspects of PCR amplification. Springer $2008 ; 34$.

Zaini A. Where is Malaysia in the midst of the Asian epidemic of diabetes mellitus? Diabetes Res ClinPract. 2000;50(Suppl 2):S23-8. 


\section{How to cite this article:}

Basavaraj C Metri and Jyothi. P 2020. Detection of Methicillin-Resistant Staphylococcus Aureus in Diabetic Foot Infections. Int.J.Curr.Microbiol.App.Sci. 9(02): 2141-2149. doi: https://doi.org/10.20546/ijcmas.2020.902.243 